\begin{abstract}
Iranica
Abstracta Iranica Revue bibliographique pour le domaine irano-aryen

Volume 34-35-36 | 2017

Comptes rendus des publications de 2011-2013
\end{abstract}

\title{
A. Vydrin. Counterfactual Mood in Iranian
}

\section{Agnès Lenepveu-Hotz}

\section{(2) OpenEdition}

\section{Journals}

Édition électronique

URL : http://journals.openedition.org/abstractairanica/41129

DOI : 10.4000/abstractairanica.41129

ISSN : 1961-960X

Éditeur :

CNRS (UMR 7528 Mondes iraniens et indiens), Éditions de l'IFRI

\section{Référence électronique}

Agnès Lenepveu-Hotz, «A. Vydrin. Counterfactual Mood in Iranian », Abstracta Iranica [En ligne], Volume 34-35-36 | 2017, document 4, mis en ligne le 15 juillet 2016, consulté le 27 septembre 2020. URL :

http://journals.openedition.org/abstractairanica/41129; DOI : https://doi.org/10.4000/

abstractairanica. 41129

Ce document a été généré automatiquement le 27 septembre 2020.

Tous droits réservés 


\title{
A. Vydrin. Counterfactual Mood in Iranian
}

\author{
Agnès Lenepveu-Hotz
}

\section{RÉFÉRENCE}

A. Vydrin. « Counterfactual Mood in Iranian », in : Agnes Korn, Geoffrey Haig, Simin Karimi, Pollet Samvelian, éds., Topics in Iranian Linguistics. Wiesbaden, Reichert, 2011, p. 71-86.

1 Peu de langues possèdent un marqueur dédié uniquement à l'expression du contrefactuel. Dans cet article, l'A. montre qu'il existe des langues iraniennes qui ont développé un tel mode, sous l'influence de langues en contact. Il passe en revue six langues iraniennes, une du moyen iranien, cinq de l'iranien moderne. Ces langues appartiennent aussi bien au groupe des langues iraniennes orientales (sogdien, ossète iron et pashto) qu'aux langues occidentales (tat, talysh et parači). Si la catégorie modale dévolue au contrefactuel en ossète et en pashto exprime également d'autres valeurs, elle est bien exclusivement marqueur du contrefactuel en tat, talysh et parači (le manque d'occurrences en sogdien ne permet pas d'être affirmatif à ce sujet). L'ossète et le pashto sont néanmoins considérés par l'A. comme possédant presque un mode contrefactuel.

2 S'appuyant sur le fait que, à l'exception du sogdien, toutes ces langues sont modernes, et que le contrefactuel n'a pas d'expression propre dans les langues anciennes et la grande majorité des langues moyennes, l'A. en déduit que l'existence d'un marqueur de contrefactuel n'est pas une caractéristique des langues iraniennes. Il propose d'y voir un emprunt aux langues en contact : langues turques pour le tat et le talysh (et peutêtre pour l'ossète), et langues indo-aryennes pour le pashto et le parači. 


\section{AUTEURS}

\section{AGNÈS LENEPVEU-HOTZ}

Université Sorbonne Nouvelle - Paris 3 